\title{
Karl Zilles (1944-2020): a personal tribute
}

\author{
Laszlo Zaborszky ${ }^{1}$
}

Published online: 24 May 2020

(c) Springer-Verlag GmbH Germany, part of Springer Nature 2020

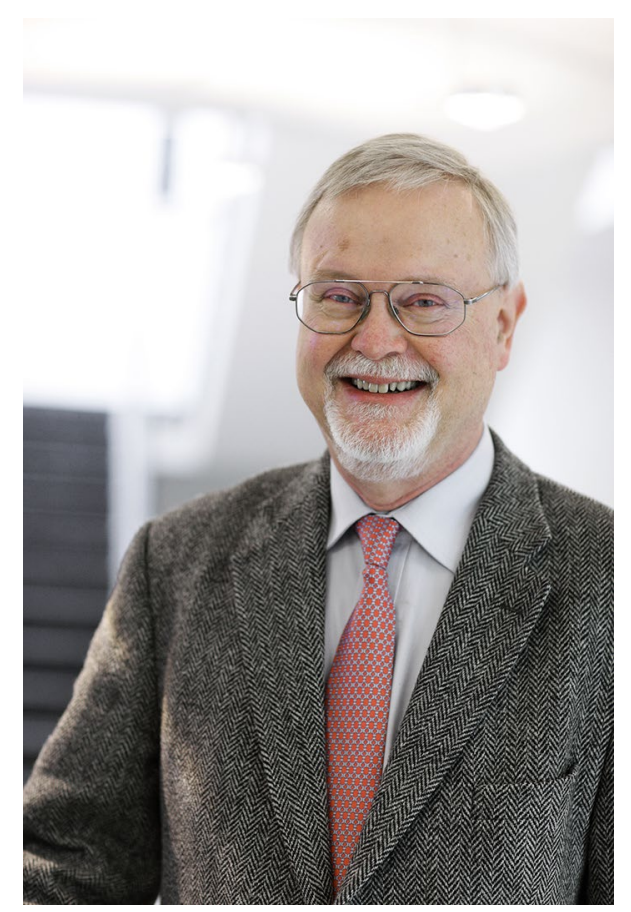

Karl Zilles, founding co-editor-in-chief of this journal, died on April 26, 2020. He was born in Würzburg, a small city in Bavaria with famous baroque architecture that was heavily damaged by allied bombing during WWII; he often visited his parents in this town. We first met in the mid 1970s, while I was on leave of absence from Semmelweis University Hungary, and I was working in the University of Würzburg anatomy department, located in the Koellikerstrasse, named after the famous anatomist whose hand was X-rayed by Roentgen, another famous professor at that university. We also met in many of the annual deliberations of the German Anatomical Society, of which he was president in

Laszlo Zaborszky

laszloz@ newark.rutgers.edu

1 Center for Molecular and Behavioral Neuroscience, Rutgers University, 197 University Avenue, Newark, NJ 07102, USA
1996/1997. He followed the best tradition of German neuroanatomical research in the cortex, but he realized the shortcomings of Brodmann's map (Brodmann 1909) that needed to be solved to be able to interpret the burgeoning in vivo human imaging data: (i) lack of observer-independent quantification, (ii) lack of data on the intrasulcular surface that makes up 2/3 of the cortical surface, (iii) lack of knowledge on interindividual differences, and (iv) lack of conversion from $2 \mathrm{D}$ to $3 \mathrm{D}$. At the time, a direct technique to compare postmortem and in vivo data was not available. To solve this problem, Karl invented two ingenious techniques: first, he established a method enabling statistical validation of the position of cortical borders, and second, donated brains were perfused, in situ imaged by T1-weighted MRI scanning and then processed with traditional histologic techniques. Cortical regions were identified using the quantitative technique, delineated on 2D images of the sections and overlaid in a reference brain: this statistically testable probabilistic 3D mapping became a standard technique in many laboratories around the world to correlate microstructural details with functional data. Before he embarked on a large-scale re-mapping of the human cerebral cortex (Amunts and Zilles 2006; Eickhoff et al. 2005), he published a definitive cytoarchitectonic map of the rat cerebral cortex (Zilles and Wree 1985). An important contribution towards defining cortical cellular architecture and hierarchical organization was the development of techniques to show the quantitative distributions of receptors and create so-called receptor "fingerprints' that characterize each cortical area (Zilles et al. 2002; Zilles and Palomero-Gallagher 2017a; Palomero-Gallagher et al. 2020). Eventually, he published the BigBrain, an ultra-high resolution 3D atlas consisting over $7000 \mathrm{sec}-$ tions (Amunts et al. 2013). Karl also analyzed cyto- and receptor architecture as well as connectivity in non-human primate brains (Zilles and Palomero-Gallagher 2017b; Zilles et al. 1982, 2016) to better understand the development of cognitive, motor, and sensory functions during brain evolution. He considered this evolutionary perspective to be a crucial aspect of his research, since studies focused on an exclusively anthropocentric interpretation do not explain 
how cognitive functions have developed by changes in the underlying microstructure and encoding strategies during evolution.

After leading the Anatomy Institute of the University of Cologne (1981-1991), he moved to Düsseldorf, chairing the Anatomy at Heinrich-Heine-University (1991-2002) and directing the C. \& O. Vogt Brain Research Institute (1991-2012). The Vogt institute, initially founded by Oscar Vogt in Berlin (whose student was also K. Brodmann) is connected with major developments in twentieth century cortical cyto- and myeloarchitectonic studies. After Vogt was dismissed by the Nazi government, the collection was stored in a hospital in the Black Forest until it became housed in the attic of the Anatomy Department in Düesseldorf. Karl's collection of human brains for cyto- and receptor studies was later moved to the Institute of Neuroscience and Medicine, Research Center Jülich, which he directed from 1998 to 2012. The processing of these brains started in the eighties and by the late 1990s, post-docs and PhD students in Düsseldorf were feverishly working on their dissertations and scientists from all over the world descended to his laboratory to see firsthand his brain collection. The large slides were literally grabbed from each other to map various brain areas.

My anatomical studies in rodents on the basal forebrain (BF) cholinergic system led to the idea that this system should participate in attention, but due to susceptible artefacts in the basal part of the brain, no reasonable person understanding imaging would have believed that one can do functional studies with cellular resolution in this structure. I approached Karl, who had already published an excellent paper on receptors in the rodent BF, asking whether I could look at his brain collections for generating a $3 \mathrm{D}$ postmortem map of the human cholinergic space that later can be used for functional studies. With his encouragement and hospitality, I spent few weeks in his department every year between 2000 and 2005.

While Karl was interested in a new parcellation of the cortex, the complex, fragmented location of cholinergic cells was a challenge, and we had to go through several improvements in scanning his human brain sections. Finally, by 2005 , we were able to create high-resolution images of the sections that could be warped with his elastic transformation method into the MNI single subject reference brain - the standard for registering human imaging data. I will never forget his smiling face when he came into the lab and showed that it was possible to warp sections with the outlined cholinergic space into the reference brain that indicated interindividual variations of this tiny structure (about $300 \mathrm{~mm}^{3}$ ), which was a real treat. Due to my tardiness, however, the paper was published only in 2008, but it was a featured article on the cover of NeuroImage (Zaborszky et al. 2008).
Through visits in Düsseldorf and later in Jülich, we had many discussions about how a common anatomical framework, unconstrained by a single technique or level of analysis, can provide an opportunity to integrate massive amount of data from genes and molecules to behavior and cognition to explore structure-function relationship from a new perspective. This framework is a prerequisite to exploring the cellular and synaptic bases of plastic changes during development and in the aging brain, both in the normal state and in a wide spectrum of neurological and psychiatric disorders. Thus, an idea for a new journal was born (Zaborszky and Zilles 2007). It was, therefore, no surprise that in the Summer of 2006, Andrea Pillmann, from Springer visited me at Rutgers University in Newark, with news that the publisher decided to re-launch Anatomy and Embryology, a journal that had been edited by Karl for many years, with a new aim and scope. She was wondering whether I would join with Karl to co-edit this journal. While there was some skepticism at the Atlanta inaugural board meeting (Society for Neuroscience, Atlanta, 2006) due to increased number of journals, we would face enormous difficulties, the new journal, BSAF filled an important niche for systems level neuroanatomy papers devoted to integrative structure-function analysis. While initially only Karl and I handled all the submissions, we eventually raised the impact factor from 2.4 (2008) to 7.8 by 2012 . It was a lot of work: we started in 2007 with only 60 submissions and reached close to 700 submissions in 2016. It was because of Karl's fame that BSAF attracted a slate of excellent scientists as section editors or authors and BSAF became a mainstream journal for scientists all over the world. We had to decline a substantial proportion of manuscripts and tighten the focus of the journal several times, considering only those manuscripts where the findings represented a sufficiently striking advance in brain structure-function relationships, the main focus of BSAF.

His immense insight into the fine structure, evolution, and function of the human brain is reflected in over 750 papers, book chapters, and textbooks. Karl was a phenomenal scholar whose passion, influence, and help contributed to shape many careers in human and comparative brain sciences. His dedication, rigor, and scientific approaches have been transformative in the field of neuroanatomy. Many section editors of this journal were fortunate to work and to live, in one time or another in our career, in Karl's special intellectual environment. Many of us met him on the balcony outside his office in Düsseldorf, during extended discussion of our projects while he smoked his pipe. Or we could share his enthusiasm for art and culture, be it in the Neue Galerie and MOMA in New York City, or in a museum hidden in a mountain of the scenic area called Shigaraki in Japan. I vividly remember sitting in his smaller office in Jülich after he officially retired, as he showed with excitement 
his high-resolution images of fiber tracts in the rat and vervet monkey using a new, polarized light microscopic technique (Zilles et al. 2016). I had a bad flu and coughed intensely but typical of Karl's humor, after my trip he thanked me that I was "not only helpful for further work on receptors (Zaborszky et al. 2015) and fibers', but also I really 'helped to booster his immune system'. Of course, the fact that air in his office was thick with smoke from his pipe (his was the only office in the entire Research Centre where you were allowed to smoke), did not help my cough! He was a scientist of high integrity, a brilliant teacher, and a kind-hearted and supportive person. We all enjoyed his and Birgit's, hospitality and their love for the Japanese garden at his home in Cologne. His passion and knowledge were infectious, and he will live on through our memories and pass along to future scientific generations.

Acknowledgement LZ is grateful to Prof. Nicola Palomare-Gallagher for providing key references and biographical data from the monumental oeuvre of K. Zilles.

\section{References}

Amunts K, Zilles K (2006) Atlases of the human brain: tools for functional neuroimaging. In: Zaborszky L, Wouterlood F, Lanciego JL (eds) Neuroanatomical tract-tracing 3: molecules, neurons and systems. Springer, New York, pp 566-603

Amunts K, Lepage C, Borgeat L, Mohlberg H, Dickscheid T, Rousseau M, Bludau S, Bazin P, Lewis L, Oros-Peusquens A, Shah N, Lippert T, Zilles K, Evans A (2013) BigBrain: an ultra-high resolution 3D human brain model. Science 340(6139):1472-1475

Brodmann K (1909) Vergleichende Lokalisationslehre der Grosshirnrinde. Verlag von Johann Ambrosius Barth, Leipzig

Eickhoff S, Stephan K, Mohlberg H, Grefkes C, Fink G, Amunts K, Zilles K (2005) A new SPM toolbox for combining probabilistic cytoarchitectonic maps and functional imaging data. NeuroImage 25:1325-1335
Palomero-Gallagher N, Kedo O, Mohlberg H, Zilles K, Amunts K (2020) Multimodal mapping and analysis of the cyto- and receptorarchitecture of the human hippocampus. Brain Struct Funct 2020:1-27

Zaborszky L, Zilles K (2007) Prologue. Brain Struct Funct 212:1-2

Zaborszky L, Hoemke L, Mohlberg H, Schleicher A, Amunts K, Zilles K (2008) Stereotaxic probabilistic maps of the magnocellular cell groups in human basal forebrain. NeuroImage 42:1127-1141

Zaborszky L, Amunts K, Palomero-Gallagher N, Zilles K (2015) Basal forebrain anatomical system in MRI space. In: Toga A (ed) Brain mapping: an encyclopedic reference. Elsevier, San Diego, pp 395-409

Zilles K, Palomero-Gallagher N (2017a) Multiple transmitter receptors in regions and layers of the human cerebral cortex. Front Neuroanat 11:78. https://doi.org/10.3389/fnana.2017.00078

Zilles K, Palomero-Gallagher N (2017b) Comparative analysis of receptor types that identify primary cortical sensory areas. In: Kaas JH (ed) Evolution of nervous systems, 2nd edn. Elsevier, Oxford, pp 225-245

Zilles K, Wree A (1985) Cortex: areal and laminar structure. In: Paxinos G (ed) The rat nervous system, vol 1. Sydney, Academic Press, pp 375-415

Zilles K, Palomero-Gallagher N, Grefkes C, Scheperjans F, Boy C, Amunts K, Schleicher A (2002) Architectonics of the human cerebral cortex and transmitter receptor fingerprints: reconciling functional neuroanatomy and neurochemistry. Eur Neuropsychopharmacol 12:587-599

Zilles K, Stephan H, Schleicher A (1982) Quantitative cytoarchitectonics of the cerebral cortices of several prosimian species. In: Armstrong E, Falk D (eds) Primate brain evolution: methods and concepts. Plenum Press, New York, pp 177-201

Zilles K, Palomero-Gallagher N, Grasel D, Schlomer P, Cremer M, Woods R, Amunts A, Axer M (2016) High-resolution fiber and fiber tract imaging using polarized light microscopy in the human, monkey, rat and mouse brain. In: Rockland KS (ed) Axons and brain architecture. Elsevier-Academic Press, Amsterdam, pp 369-389

Publisher's Note Springer Nature remains neutral with regard to jurisdictional claims in published maps and institutional affiliations. 